\title{
Analisa Vegetasi Hutan Mangrove Di Selat Pogo-Pogo Kabupaten Halmahera Selatan
}

\section{Mangrove Forest Vegetation Analysis in the Pogo-Pogo Strait South Halmahera Regency}

\author{
Laswi Irmayanti ${ }^{1}$, Muhammad Nur ${ }^{2}$, Sadam Husain M. Mayor ${ }^{2}$, M.Charis Kamarullah ${ }^{3}$ \\ ${ }^{1}$ Program Studi Kehutanan. Fakultas Pertanian. Universitas khairun \\ ${ }^{2}$ Program Studi Kehutanan. Sekolah Tinggi Pertanian Labuha \\ ${ }^{3}$ Program Studi Perikanan. Sekolah Tinggi Pertanian Labuha \\ E-mail: kehutananstp@gmail.com
}

\begin{abstract}
Mangrove ecosystems have a very important role for the coastal environment, both in terms of physical, ecological and economic. One of the important mangrove areas in South Halmahera is on the coast of Pogo-Pogo island. The purpose of this study was to identify the diversity and dominance of mangrove species in the Pogo-Pogo Strait. Research uses the method of the plot lanes. The types of mangroves found in the research location were 9 species, 3 of which were categorized as true mangrove and 6 types of asociate mangrove. The diversity of mangroves found at the study site was relatively low. The Shannon-Wienner species diversity index $\left(H^{\prime}\right)$ for seedling $\left(H^{\prime}=0.59\right)$, sapling $\left(H^{\prime}=0.00\right)$, and tree $\left(H^{\prime}=\right.$ 0.66). This indicates that the distribution of individual numbers of each species was lowed and the stability of the mangrove forest community in the Pogo-Pogo strait was lowed. In all level of growth (seedlings, saplings and trees), the Rhizophora mucronata was the most dominating species.
\end{abstract}

Key words: mangrove, diversity, pogo-pogo

\section{Pendahuluan}

Sebagian besar daerah pesisir pantai pulau-pulau di Indonesia merupakan tempat tumbuh mangrove yang baik, sehingga mangrove merupakan suatu ekosistem yang umum mencirikan morfologi sistem biologi pesisir di Indonesia (Kusmana 2009). Lignon et al. (2011) melaporkan bahwa mangrove memiliki banyak fungsi, diantaranya adalah sebagai penjaga dari erosi, gelombang laut, dan wahana rekreasi, serta manfaat langsung berupa hasil hutan. Mangrove juga berfungsi sebagai tempat pemijahan dan tempat mencari makan ikan dan biota laut lainnya (Giri et al. 2008 dan Deshmukh \& Balaji 1994). Selain itu, mangrove juga merupakan tempat untuk mencari makan bagi burung-burung tertentu (ITTO 2003).

Sebagai salah satu ekosistem pesisir, hutan mangrove merupakan ekosistem yang unik dan rentan terhadap gangguan. Pertambahan penduduk terutama di daerah pantai, mengakibatkan adanya perubahan tataguna lahan dan pemanfaatan sumberdaya alam secara berlebihan, sehingga hutan mangrove dengan cepat akan menipis dan rusak (Ningsih 2008). Permasalahan utama pada habitat mangrove bersumber dari berbagai tekanan yang menyebabkan luas hutan mangrove semakin berkurang, antara lain oleh kegiatan pemukiman, tambak, ataupun berbagai kegiatan pengusahaan hutan lainnya. 
Potensi sumberdaya pesisir sepatutnya dikembangkan untuk meningkatkan kesejahtraan masyarakat, misalnya dengan mengidentifikasi potensi mangrove yang layak dikembangkan sebagai daerah tujuan ekowisata (Bahar 2004). Pengembangan ekowisata mangrove akan mengurangi pemanfaatan mangrove yang bersifat eksploitatif, misalnya konversi mangrove untuk areal pertambakan.

Salah satu lokasi di Kabupaten Halmahera Selatan yang potensial dikembangkan untuk tujuan ekowisata adalah ekosistem hutan mangrove di Selat Pogo Pogo, Desa Kusubibi, Kecamatan Bacan Barat. Pengembangan ekowisata tersebut harus diiringi dengan pendataan potensi yang ada di hutan mangrove. Dengan adanya data potensi tersebut, maka akan mudah untuk menentukan strategi pengembangan ekowisata. Pendataan potensi mangrove bisa dilaksanakan dengan analisa vegetasi hutan mangrove. Oleh karena itu peneliti melaksanakan penelitian analisis vegetasi mangrove di Selat Pogo-Pogo. Tujuan dari penelitian ini adalah untuk mengidentifikasi keanekaragaman dan dominansi jenis mangrove di Selat Pogo-Pogo.

\section{Metode Penelitian}

\subsection{Waktu dan Tempat}

Penelitian dilaksanakan di pesisir pantai Pulau Pogo-Pogo. Penelitian dilaksanakan selama 3 bulan, yaitu bulan Januari-Maret 2018.

\subsection{Metode Penelitian}

Pengambilan data dan pengamatan vegetasi mangrove dilakukan dalam jalur berpetak pada posisi tegak lurus garis pantai, dengan lebar jalur 10 meter dan panjang jalur 100 meter. Prosedur pengambilan data dan pengamatan vegetasi mangrove ini menggunakan modifikasi sesuai yang dilakukan oleh Ashton dan Macintosh (2002) serta Ningsih (2008). Jalur dibagi menjadi 10 plot dengan ukuran $10 \mathrm{~m}$ x 10m (untuk pengukuran tingkat pohon). Pada setiap plot dibuat subpetak dengan ukuran $5 \mathrm{~m}$ x $5 \mathrm{~m}$ untuk pancang dan $2 \mathrm{~m}$ x $2 \mathrm{~m}$ untuk pengukuran tingkat pancang. Desain plot penelitian disajikan pada Gambar 1.

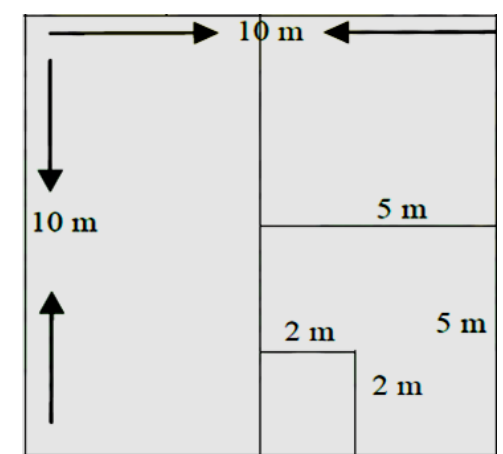

Gambar 1. Desain plot penelitian mangrove

Identifikasi setiap jenis mangrove berdasarkan bentuk daun, buah, bunga, batang dan akar untuk penentuan jenis mangrove dilakukan dengan buku panduan pengenalan mangrove di Indonesia (Noor et al. 2012). Identifikasi jenis vegetasi mangrove dilakukan pada semua tingkatan permudaaan yang ditemukan dalam plot penelitian, yaitu:

a) tingkat semai, yaitu permudaan mulai kecambah sampai tingginya $1.5 \mathrm{~m}$

b) tingkat pancang, yaitu tingkat permudaan dengan tinggi lebih dari $1.5 \mathrm{~m}$ dan diameter batangnya kurang dari $10 \mathrm{~cm}$

c) tingkat pohon, yaitu tumbuhan berkayu yang mempunyai diameter batang $\geq 10 \mathrm{~cm}$

Permudaan pada tingkat semai dicatat nama lokal dan ilmiah serta dihitung jumlahnya. Pada tingkat pancang dan pohon dicatat nama lokal dan ilmiah, dihitung jumlah individu, diukur tinggi dan diameter batang dari setiap individu. 


\subsection{Analisa Data}

\section{1) Indek Keanekaragaman Jenis}

Untuk mengetahui keanekaragaman jenis dihitung dengan menggunakan rumus Shannon-Wienner (Odum, 1996), sebagai berikut:

keterangan:

$$
\mathrm{H}^{\prime}=-\sum \frac{\mathrm{ni}}{\mathrm{N}} \ln \frac{\mathrm{ni}}{\mathrm{N}}
$$

ni : Jumlah individu tiap jenis

$\mathrm{N} \quad$ : Jumlah seluruh individu

H' : Indeks Keragaman Shannon-Wiener

\section{2) Indek Nilai Penting (INP)}

INP dihitung berdasarkan penjumlahan nilai Kerapatan Relatif (KR), Frekuensi Relatif (FR) dan Dominansi Relatif (DR). Persamaan untuk menghitung kerapatan jenis, Frekuensi, Dominansi, dan Indeks Nilai Penting dalam penelitian ini mengacu pada Kainde et al. (2011), yaitu :

$$
\begin{gathered}
\text { Kerapatan }(\mathrm{K})=\frac{\text { Jumlah individu }}{\text { Luas petak ukur }} \\
\text { Kerapatan Relatif }(\mathrm{KR})=\frac{\text { Kerapatan suatu jenis }}{\text { Kerapatan seluruh jenis }} \times 100 \% \\
\text { Frekuensi }(\mathrm{F})=\frac{\text { Jumlah petak ditemukan suatu jenis }}{\text { Jumlah seluruh petak }} \\
\text { Frekuensi Relatif (FR) }=\frac{\text { Frekuensi suatu jenis }}{\text { Frekuensi seluruh jenis }} \times 100 \% \\
\text { Dominansi (D) }=\frac{\text { Luas bidang dasar suatu jenis }}{\text { Luas petak ukur }} \\
\text { Dominansi Relatif (DR) }=\frac{\text { Dominansi suatu jenis }}{\text { Dominansi seluruh jenis }} \times 100 \% \\
\text { Indeks nilai penting (INP) }=\text { KR }+ \text { FR }+ \text { DR (untuk pohon) } \\
\text { Indeks nilai penting (INP) }=\text { KR }+ \text { FR (untuk pancang dan semai) }
\end{gathered}
$$

\section{Hasil dan Pembahasan}

\subsection{Keanekaragaman Jenis}

Berdasarkan hasil identifikasi yang telah dilakukan ditemukan 9 jenis pohon mangrove yang termasuk ke dalam 8 Famili (Tabel 1). Diantara vegetasi mangrove yang ditemukan, 3 jenis diantaranya termasuk kategori mangrove sejati (true mangrove) dan 6 jenis mangrove ikutan (asociate mangrove). Mangrove ikutan merupakan jenis lain yang ditemukan di sekitar mangrove (Noor et al. 2012), dan cenderung hanya tumbuh pada habitat teresterial (Mukhlisi et al. 2013).

Mangrove sejati merupakan jenis tanaman yang hidup di wilayah pasang surut dan mampu menyerap zat garam sekaligus memiliki sistem adaptasi mengeluarkan kelebihan zat garam yang tidak dibutuhkan melalui batang dan daunnya. Meskipun ada juga yang hidup di 
darat, karena biji yang terbawa oleh hewan hingga ke darat, namun selama jenis ini mampu menyerap dan mengeluarkan kelebihan zat garam maka termasuk mangrove sejati. Inilah indikasi dari mangrove sejati yaitu mampu menyerap zat garam dari tanah dan mengeluarkannya dari tubuh. Berdasarkan hasil penelitian (Tabel 1) jenis mangrove sejati yang ditemukan pada lokasi penelitian yaitu: Excoecaria agallocha, Rhizophora mucronata, dan Xylocarpus grandtum.

Vegetasi mangrove mempunyai daya adaptasi yang khas terhadap lingkungan. Lebih lanjut Bengen (2001) menguraikan jika adaptasi fisiologis mangrove dilakukan terhadap beberapa hal sebagai berikut (1) kadar oksigen rendah dengan membentuk perakaran yang memiliki pneumatophora (contonya Avicennia spp, Xylocarpus sp. dan Sonneratia spp) serta lentisel (seperti Rhizophora spp), (2) konsentrasi garam tinggi dengan memiliki stomata khusus untuk mengurangi penguapan, daun yang kuat dan tebal dan sel-sel khusus pada daun untuk menyimpan garam (3) stabilitas tanah dan kondisi pasang surut dengan mengembangkan struktur perakaran esktensif yang berfungsi memperkokoh, mengambil unsur hara serta menahan sedimen.

Mangrove ikutan merupakan jenis tanaman yang mampu beradaptasi dengan ekosistem pantai namun yang menjadi pembeda dari mangrove sejati adalah ketidakmampuan mengeluarkan kelebihan zat garam dari dalam tubuh. Dalam penelitian ini ditemukan 6 jenis mangrove ikutan, yaitu: Morinda citrifolia, Pandanus odoratissima, Paraserianthes falcataria, Pongamia pinnata, Scaevola taccada, dan Terminalia catappa.

Tabel 1. Jenis-jenis mangrove yang ditemukan pada lokasi penelitian

\begin{tabular}{|c|c|c|c|}
\hline No & Jenis & Famili & $\begin{array}{c}\text { Kategori Mangrove } \\
\text { Berdasarkan Noor } \text { et al. } \text { (2012) }\end{array}$ \\
\hline 1 & Excoecaria agallocha & Euphorbiaceae & Mangrove Sejati \\
\hline 2 & Morinda citrifolia & Rubiaceae & Mangrove Ikutan \\
\hline 3 & Pandanus odoratissima & Pandanaceae & Mangrove Ikutan \\
\hline 4 & Paraserianthes falcataria & Leguminosae & Mangrove Ikutan \\
\hline 5 & Pongamia pinnata & Leguminosae & Mangrove Ikutan \\
\hline 6 & Rhizophora mucronata & Rhizophoraceae & Mangrove Sejati \\
\hline 7 & Scaevola taccada & Goodeniaceae & Mangrove Ikutan \\
\hline 8 & Terminalia catappa & Combretaceae & Mangrove Ikutan \\
\hline 9 & Xylocarpus grandtum & Meliaceae & Mangrove Sejati \\
\hline
\end{tabular}

Keanekaragaman jenis merupakan suatu karakteristik tingkat komunitas berdasarkan organisasi biologinya yang dapat digunakan untuk menyatakan struktur komunitas (Dendang 2009). Keanekaragaman jenis juga merupakan parameter yang sangat berguna untuk membandingkan komunitas, terutama untuk mempelajari pengaruh gangguan biotik, untuk mengetahui tingkatan suksesi atau kestabilan suatu komunitas. Beberapa indeks keanekaragaman spesies yang sering digunakan dalam pemantauan keanekaragaman hayati dan ekologi adalah indeks Shannon-Wienner atau H', yaitu keanekaragaman tinggi $\left(\mathrm{H}^{\prime}>3\right)$, keanekaragaman sedang $\left(\mathrm{H}^{\prime}=1-3\right)$, dan keanekaragam rendah $\left(\mathrm{H}^{\prime}<1\right)$ (Ian dan Peter 2003).

Berdasarkan hasil perhitungan indeks keanekaragaman jenis Shannon-Wienner (H') pada lokasi penelitian untuk masing-masing strata pertumbuhan yaitu : semai $\left(\mathrm{H}^{\prime}=0.59\right)$, pancang $\left(H^{\prime}=0.00\right)$, dan pohon $\left(H^{\prime}=0.66\right)$. Nilai keanekaragaman tersebut tergolong pada keanekaragam rendah. Hal ini berarti penyebaran jumlah individu tiap jenis rendah dan kestabilan komunitas hutan mangrove di Selat Pogo-Pogo tergolong rendah.

Secara alami keanekaragaman jenis hutan mangrove memang lebih rendah bila dibandingkan hutan tropis namun memiliki struktur dan fungsi yang mampu 
mempertahankan hidupnya pada lingkungan ekstrim di zona pasang surut (Duke et al. 1998). Dari ketiga strata pertumbuhan vegetasi mangrove yang ada di Selat Pogo-Pogo, pancang memiliki nilai keanekaragaman 0.00 . Hal ini karena pada strata pancang hanya ditemukan 1 jenis, yaitu R.mucronata. Nilai keanekaragaman suatu komunitas sangat bergantung pada jumlah jenis dan jumlah individu yang terdapat pada komunitas tersebut (Akbar et al. 2017).

\subsection{Dominansi Jenis}

Soerianegara dan Indrawan (2005) melaporkan bahwa INP (Indeks Nilai Penting) digunakan untuk menetapkan dominansi suatu jenis terhadap jenis lainnya. Nilai INP merupakan nilai yang sangat penting dalam menentukan seberapa besar peran dan fungsi suatu jenis dalam suatu ekosistem. INP dihitung berdasarkan penjumlahan nilai Kerapatan Relatif (KR), Frekuensi Relatif (FR) dan Dominansi Relatif (DR) untuk strata pohon, sedangkan untuk strata pancang dan semai adalah penjumlahan KR dan FR. Hasil INP penelitian ini pada masing-masing jenis untuk setiap strata pertumbuhan disajikan secara lengkap pada Tabel 2, 3 dan 4.

Tabel 2. Indeks Nilai Penting strata pohon

\begin{tabular}{|c|l|c|c|c|c|}
\hline No & \multicolumn{1}{|c|}{ Jenis } & KR $(\boldsymbol{\%})$ & FR $(\%)$ & DR $(\%)$ & INP $(\%)$ \\
\hline 1 & R. mucronata & 83.33 & 69.23 & 88.76 & 241.32 \\
\hline 2 & E. agallocha & 2.38 & 7.69 & 1.25 & 11.32 \\
\hline 3 & P.odoratissima & 4.76 & 7.69 & 1.78 & 14.23 \\
\hline 4 & P. falcataria & 7.14 & 7.69 & 7.51 & 22.35 \\
\hline 5 & X. grandtum & 2.38 & 7.69 & 0.70 & 10.78 \\
\hline \multicolumn{2}{|c|}{ Jumlah } & 100 & 100 & 100 & 300 \\
\hline
\end{tabular}

Tabel 3. Indeks Nilai Penting strata pancang

\begin{tabular}{|c|c|c|c|c|}
\hline No & Jenis & KR (\%) & FR (\%) & INP (\%) \\
\hline 1 & R. mucronata & 100 & 100 & 200 \\
\hline \multicolumn{2}{|c|}{ Jumlah } & 100 & 100 & 200 \\
\hline
\end{tabular}

Tabel 4. Indeks Nilai Penting strata Semai

\begin{tabular}{|c|c|c|c|c|}
\hline No & Jenis & KR (\%) & FR $(\%)$ & INP $(\%)$ \\
\hline 1 & Rhizophora mucronata & 85.71 & 60.00 & 145.71 \\
\hline 2 & Pongamia pinnata & 3.17 & 10.00 & 13.17 \\
\hline 3 & Terminalia catappa & 1.59 & 10.00 & 11.59 \\
\hline 4 & Scaevola tacada & 3.17 & 10.00 & 13.17 \\
\hline 5 & Morinda citrifolia & 6.35 & 10.00 & 16.35 \\
\hline \multicolumn{2}{|r|}{ Jumlah } & 100 & 100 & 200 \\
\hline
\end{tabular}

INP pada semua strata pertumbuhan, jenis $R$. mucronata (untuk pohon $241.32 \%$, pancang $200 \%$ dan semai $145.71 \%$ ) menjadi jenis mangrove dengan tingkat penguasaan tertinggi. Kehadiran suatu jenis pohon pada daerah tertentu menunjukkan kemampuan pohon tersebut untuk beradaptasi dengan kondisi lingkungan setempat, sehingga jenis yang mendominasi suatu areal dapat dinyatakan sebagai jenis yang memiliki kemampuan adaptasi dan toleransi yang lebar terhadap kondisi lingkungan.

$R$. mucronata merupakan jenis mangrove yang menyukai substrat berlumpur (Bengen 2000). Kondisi tanah mangrove pada zona terbuka di Pogo-Pogo merupakan substrat 
berlumpur sehingga didominasi oleh $R$. mucronata. Noor et al. (2012) memaparkan bahwa secara sederhana, mangrove umumnya tumbuh dalam 4 zona, yaitu pada daerah terbuka, daerah tengah, daerah yang memiliki sungai berair payau sampai hampir tawar, serta daerah ke arah daratan yang memiliki air tawar. Zona terbuka mangrove kondisi tanahnya biasanya berupa pasir dan beberapa berupa lumpur.

\section{Kesimpulan}

Jenis mangrove yang ditemukan di lokasi penelitian yaitu 9 jenis, 3 jenis diantaranya termasuk kategori mangrove sejati (true mangrove) dan 6 jenis mangrove ikutan (asociate mangrove). Keanekaragaman mangrove yang ditemukan di lokasi penelitian tergolong rendah. Hal ini berarti penyebaran jumlah individu tiap jenis rendah dan kestabilan komunitas hutan mangrove di Selat Pogo-Pogo tergolong rendah. Pada semua strata pertumbuhan (semai, pancang dan pohon), jenis Rhizophora mucronata merupakan jenis yang paling mendominasi.

\section{Daftar Pustaka}

Akbar N, Marus I, Haji I, Abdullah S, Umalekhoa S, Ibrahim FS, Ahmad M, Ibrahim A, Kahar A, Tahir I. 2017. Struktur komunitas hutan mangrove di Teluk Dodinga Kabupaten Halmahera Barat Provinsi Maluku Utara. Jurnal Enggano. Vol2(1):78-89.

Ashton EC, Macintosh DJ. 2002. Preliminary assessment of the plat diversity and community ecology of the Sematan mangrove forest, Sarawak, Malaysia. Forest Ecology and Management. 166:111-129.

Bahar A. 2004. Kajian kesesuain dan daya dukung ekosistem mangrove untuk pengembangan ekowisata di gugus pulau Tanakeke Kabupaten Takalar Sulawesi Selatan [Tesis]. Bogor: Institut Pertanian Bogor

Bengen, D.G. 2000. Sinopsis Ekosistem dan Sumberdaya Alam Pesisir. Pusat Kajian Sumberdaya Pesisir dan Lautan, Institut Pertanian Bogor. Bogor.

Dendang B. 2009. Keragaman kupu-kupu di resort selabintana Taman Nasional Gunung Gede Pangrango, Jawa Barat. J Penelitian Hutan dan Konservasi Alam Vol. VI No. 1 : 25-36, 2009.

Deshmukh SV, Balaji V. 1994. Conservation of Mangrove Forest Genetic Resouces. MadrasIndia: M.S. Swaminathan Research Foundation. Centre for Research on Sustainable Agricultural, and Rural Development (CRSARD).

Duke, N.C., M C. Ball and J.C. Ellison. 1998. Factors influencing biodiversity and distributional gradients in mangroves. Global Ecology and Biogeography Letters 7 (1): 27-47.

Giri C, Zhu Z, Tieszen II, Singh A, Gillette S, Kelmelis JA. 2008. Mangrove forest distributions and dynamics (1975-2005) of the tsunami-affected region of Asia. Journal of Biogeography. 35:519-528.

Ian, Peter. 2003. A tribute to claude Shannon (1916-2001) and a plea for more rigorous use of species richness, species diversity and the 'Shannon-Wiener' Index. J Global Ecology \& Biogeography 177-179.

[ITTO] International Tropical Timber Organization. 2003. Mangroves Forests Worth their Salt. Yakohama-Japan: ITTO

Kainde RP, Ratag SP, Tasirin JS, Faryanti D. 2011. Vegetation analysis of the mount Tumpa Protection Forest. Eugenia. 17(3). 
Kusmana C. 2009. Pengelolaan system mangrove secara terpadu. Workshop Pengelolaan Ekosistem Mangrove di Jawa Barat, di Hotel Khatulistiwa-Jatinangor, 18 Agustus 2009

Lignon MC, Jr CC, Almeida R, Menghini RP, Novelli YS, Cintron G, Guebas D. 2011. Characterisation of mangrove forest types in view of conservation and management: a review of mangals at the Cananéia region, São PauloState, Brazil. Journal of Coastal Research. 57: 349 - 353.

Mukhlisi, Hendrarto IGNB, Purnaweni. 2013. Keanekaragaman jenis dan struktur vegetasi mangrove di Desa Sidodadi Kecamatan Padang Cermin Kabupaten Pesawaran Provinsi Lampung. Prosiding Seminar Nasional Sumberdaya Alam dan Lingkungan 2013

Ningsih SS. 2008. Inventarisasi Hutan Mangrove Sebagai Bagian dari Upaya Pengelolaan Wilayah Pesisir Kabupaten Dili Serdang [tesis]. Medan: Sumatera Utara.

Noor YR, Khazali M, Suryadiputra INN. 2012. Panduan Pengenalan Mangrove di Indonesia. Bogor: PHKA/WI-IP

Odum EP. 1996. Dasar-dasar ekologi (T. Samingan, Terjemahan). Yogyakarta: Gadjah Mada University Press.

Soerianegara, I dan Indrawan A. 2005. Ekologi Hutan Indonesia. Bogor : Fakultas Kehutanan Institut Pertanian Bogor. 